\title{
A prospective investigation of the impact of smoking bans on tobacco cessation and relapse
}

\author{
Daniel R Longo, Jane C Johnson, Robin L Kruse, Ross C Brownson, John E Hewett
}

Center for Family Medicine Science in the Department of Family and

Community Medicine, School of Medicine, University of Missouri-Columbia, Columbia, Missouri, USA

D R Longo

R L Kruse

Office of Research Support, Kirksville College of Osteopathic Medicine, Kirksville,

Missouri

J C Johnson

Department of Community Health and Prevention Research Center, School of Public

Health, Saint Louis University, Saint Louis, Missouri R C Brownson

Department of Statistics, Biostatistics Unit of Integrated Technology Services, School of Medicine, College of Arts and Sciences, University of Missouri-Columbia

J E Hewett

Correspondence to: Dr Daniel R Longo, University of

Missouri-Columbia, Family and Community Medicine, MA306N Medical Sciences Building, Columbia, Missouri 65212, USA

LongoD@health.missouri.edu

Received 9 November 2000 and in revised form

22 March 2001 . Accepted 23 March 2001

\begin{abstract}
Background and objectives-To examine the long term impact of workplace smoking bans on employee smoking cessation and relapse. Over three years we studied a total of 1033 current or former smokers (intervention group) employed in smoke-free hospitals and 816 current or former smokers (comparison group) employed in non-smoke-free workplaces. The design of this natural experiment is a prospective cohort study. We randomly selected both hospitals and employees from 12 strata based on hospital size and state tobacco regulations, and sampled employees in the same communities. Main outcome measures were post-ban quit ratio and relapse rate.

Research design-Between groups comparisons were conducted using the Cochran-Mantel-Haenszel statistic for general association, stratified Cox proportional hazards models, and the CMH analysis of variance statistic based on ranks. McNemar's test and the sign test were used to test for changes over time within each group.
\end{abstract}

Results-Differences in the post-ban quit ratio were observed between intervention and comparison groups $(p \leqslant 0.02)$. For employees whose bans were implemented at least seven years before survey, the post-ban quit ratio was estimated at 0.256 , compared with 0.142 for employees in non-smoke-free workplaces $(p=0.02)$. After controlling for a variety of factors, time to quit smoking was shorter for the hospital employees $(p<0.001)$, with an overall relative risk of quitting of 2.3 . Contrary to expectations, relapse rates were similar between the groups.

Conclusion-Employees in workplaces with smoking bans have higher rates of smoking cessation than employees where smoking is permitted, but relapse is similar between these two groups of employees. The results of this investigation have international applicability for policy makers, clinicians, employers, and employees. Countries should review smoking policies in workplaces in light of their own smoking patterns and efforts to deal with environmental tobacco smoke.

(Tobacco Control 2001;10:267-272)

Keywords: smoking cessation; smoking relapse; tobacco addiction; tobacco dependence; smoking bans; employee health; workplace health; workplace smoking
There is international concern over smoking in the workplace and other public places, especially with regard to environmental tobacco smoke (ETS). ${ }^{1-4}$ The European Commission reports that passive smoking is responsible for over 22000 deaths each year in the European Union. ${ }^{5}$ Many employers have used workplace smoking bans to address such concerns. In 1989, the Council of Health Ministers of the European Community adopted a joint resolution urging the 12 member states to adopt legislation restricting smoking in public places. Further, researchers from many countries $^{6-9}$ have documented the important side benefit of workplace smoking bans-not only are non-smokers protected from ETS, but smokers who work in settings with such bans increasingly quit smoking. Since most adults spend over one third of their waking hours at work, workplace smoking bans have the potential to influence employees' smoking behaviour both in and outside the workplace..$^{80-15}$

Smoking is a behaviour pattern that is highly resistant to change and relapse rates are high. ${ }^{16}$ It is estimated that up to $75 \%$ of smokers who quit will relapse within the first year. ${ }^{17}$ Among 17 million US adults who attempted cessation in 1991, only $14 \%$ were still abstinent 12 months later. ${ }^{18}$ While there are a number of studies of workplace smoking bans, they generally study employees at one workplace and are cross-sectional. ${ }^{12} 1315$ Little is known about the longer term impact of such bans on cessation and relapse. This prospective study is aimed at filling this gap.

When the major hospital accrediting body, the Joint Commission on Accreditation of Healthcare Organizations (JCAHO), mandated smoke-free hospitals in 1993, it provided the opportunity for a natural experiment. We first studied US hospital compliance with the new standards and reported predictors of compliance. ${ }^{6}$ Next, in a cross-sectional study, we surveyed hospital and community employees about their smoking behaviour before and after the date of the hospital's smoking ban. ${ }^{19}$ All community employees worked in locations where smoking was allowed. Despite pre-ban differences in smoking intensity, the overall difference in post-ban quit ratios remained significant even after multivariate adjustment for socioeconomic and demographic variables and smoking intensity. However, a cross-sectional study cannot address relapse and may not accurately estimate the true impact of the bans and resulting implications for mortality and 
morbidity. ${ }^{20}$ Therefore, we conducted this prospective study which includes an analysis of the impact of relapse on quit rates.

\section{Methods}

HYPOTHESES

We assessed the impact of a national workplace smoking ban on the smoking behaviour of employees. Our hypotheses were that full time employees of workplaces with smoke-free policies (total smoking ban) in comparison to employees of workplaces where smoking was permitted: (1) experience a higher post-ban quit ratio; (2) quit smoking sooner; and (3) have lower relapse rates.

\section{STUDY DESIGN}

We used a quasi-experimental design to compare employees in hospitals (where smoking was banned) to employees in the same communities who worked in locations where smoking was permitted. Taking advantage of this unique natural experiment, we surveyed hospital and community employees beginning in 1994. Respondents were re-surveyed twice to assess their smoking status prospectively.

The study had a two factor design (group and time) with repeated measures on one factor (time). A stratified random sample of US hospitals was used to ensure the accuracy of estimates and to provide adequate representation across hospital sizes and state characteristics. We used two levels of stratification. US states were divided into three groups based on intensity of tobacco cultivation and level of state tobacco taxation. These groups were further divided into four groups based on hospital bed size, yielding a total of 12 strata.

Our survey sample was chosen to detect a $5 \%$ difference in the quit rate with $80 \%$ power. ${ }^{19}$ Within each stratum we randomly selected at least two hospitals to achieve a representative sample of employees. To achieve the desired sample size of 1469, 26 hospitals were selected. Employees were randomly selected from lists provided by each hospital. Since only full time hospital employees were studied, all physicians were excluded. (Employed physicians account for only $1.2 \%$ of the total number of US hospital employees.) ${ }^{21}$

The intervention group was full time hospital employees at least 18 years of age who were either current or former smokers at the time the smoking ban was implemented in their hospital. Assessment of smoking status was relative to the time the smoking ban was implemented in each hospital, whether or not the respondent was employed in the hospital at that time. The same date was used to assess smoking status of non-hospital employees in the same community. Since we began examining smoking status at the time of the ban in each hospital, we have data regarding smoking status for longer periods of time for employees of hospitals that banned smoking earlier.

Given the relation in the US between the first five telephone digits (excluding area code) and the place of residence, we used telephone numbers to select the community comparison group. This allowed some degree of matching between hospital and community employees by socioeconomic factors. While some caution should be exercised in the interpretation of findings, given the options available at the time of this natural experiment, this was the most practical choice for the selection of the comparison group. Since the smoking ban was implemented in all US hospitals, a randomised controlled trial was prohibited.

We surveyed all participants by telephone. Respondents to the first survey were resurveyed in each of the following two years. Only respondents who were continuously employed in workplaces with the same policy type (no-smoking or smoking) as they were at the first survey are included in this analysis. Few employees moved to workplaces with a different type of smoking policy (in fact, there were too few to analyse). The survey instrument was adapted from the Behavioral Risk Factor Surveillance Survey, ${ }^{22}$ and work of the National Heart, Lung, and Blood Institute. ${ }^{23-25}$

\section{OUTCOME MEASURES}

Primary outcome measures were the post-ban quit ratio and relapse rate. Quit ratio is defined as the number of former smokers divided by the number of ever smokers (current and former smokers) at a given point in time. ${ }^{26}{ }^{27} \mathrm{As}$ we were interested in smoking cessation relative to the ban, we used the post-ban quit ratio, defined as the quit ratio at a particular time after the ban among ever smokers who were smoking when the ban was implemented. For the comparison group, measurement was similar, using time points relative to ban implementation in the corresponding community hospital. Relapse rate was defined as the percentage of smokers who were not smoking at the first survey and later resumed smoking. For example, in a hospital that banned smoking in 1990, we surveyed hospital employees in 1994 who were either current or former smokers at the time of the ban in 1990 . We asked if they had quit or resumed smoking since that time. They were similarly assessed in the two subsequent surveys if they had not moved to a workplace that permitted smoking.

STATISTICAL METHODS

In all between-group comparisons, we accounted for the pairing of a hospital and community by treating each pair as a stratum. To determine whether the two groups differed on the post-ban quit ratio at specific time intervals, we used the Cochran-MantelHaenszel statistic for general association ${ }^{28}$ for the last observation on a given subject. The result of a goodness-of-fit test indicated that the proportional hazards assumption was not violated. We compared the two groups for the time from implementation of the smoking ban to cessation of smoking with a stratified Cox proportional hazards model, ${ }^{29}$ using the most recent survey for a given subject. We included variables as covariates in the proportional hazards model if the hospital and community respondents differed significantly for a variable 
or if the variable was related to the post-ban quit ratio.

We determined whether changes occurred within each group from the first survey to the second, and also from the first survey to the third. Only subjects with data at all three surveys, and whose workplace smoking policy remained constant over all three years, were analysed. We used McNemar's test to determine whether there was a change in smoking status for each group. Additionally, we addressed the question of whether the changes differed between the two groups. To compare the two groups on relapse rates, for those who were not smoking at the time of the first survey, we compared the two groups on smoking status at the second and third surveys using the Cochran-Mantel-Haenszel statistic for general association. $^{28}$ This test also compared the groups on smoking status at the second and third surveys for those who were smoking at the first survey.

\section{Results}

Participating hospitals were compared with all hospitals that returned a survey in an earlier phase of this study. ${ }^{30}$ Twenty six variables were used for the comparison, including profit status, size, staffing full time equivalents, presence of services (for example, psychiatric, patient education, American Cancer Society approved cancer programme, worksite health promotion), type of hospital (children's, general medical/surgical, psychiatric), type of smoking policy, and whether the hospital provided smoking cessation assistance to its employees. Participating hospitals did not differ from all other hospitals on any of these characteristics.

Our response rates for the first survey were $84 \%$ for hospital employees and $66 \%$ for the community comparison group. Of the community respondents who completed the first survey, 57\% completed the second survey and $48 \%$ completed the third survey. Of hospital respondents, $69 \%$ of the respondents from the first survey completed the second, and 59\% completed the third.

At baseline the two groups differed on some characteristics, including age $(p=0.003)$, sex $(p<0.001)$, education level $(p=0.002)$, and job classification $(p<0.001)$. While the two populations differed statistically on age, the absolute difference was small. Mean age was 3.5 years higher among hospital employees. Consequently, in the Cox proportional hazards model these four variables were used as covariates to control for potential confounding. Although the two groups did not differ in social class, it was included in the model as it was related to the outcome variables. Race and preban smoking intensity did not differ between the two groups.

Estimates of the post-ban quit ratios and 95\% confidence intervals for the intervention and comparison groups are presented in table 1. Hospitals implemented smoking bans from 1987 to 1994, giving respondents a variety of start dates. Respondents from hospitals with later ban dates were followed for fewer years, causing numbers of respondents to appear to drop through time. There were significant differences for the post-ban quit ratios comparing the hospital and community employees for the first through seventh years post-ban $(\mathrm{p}=0.001$ to 0.02 ). At each of the time periods examined, the post-ban quit ratio for the hospital employees was higher than that for the community employees. The odds ratios for quitting, adjusted for hospital-community pairings, of hospital employees compared with community employees for the seven years ranged from 1.58 at five years post-ban to 2.40 at six years postban.

Cox proportional hazards model results (using the most recent survey for each subject) indicate that time to quit smoking was shorter for the hospital employees than for the community comparison group $(\mathrm{p}<0.001)$, with an overall hazard ratio of quitting of 2.5 (95\% confidence interval (CI) 1.8 to 3.6 ) (fig 1). It is important to note that a vertical line drawn through the graph at a given time does not represent a single date, but rather time since implementation of the smoking ban for each respondent. The confidence limits for the last two years are quite large because only one hospital implemented its ban in 1987, and three in 1988, leaving few respondents with eight or nine years of smoking history. After controlling for a variety of factors, such as socioeconomic and demographic characteristics (table 2), the hazard ratio decreased

Table 1 Post-ban quit ratio by time interval since implementation of smoking ban, US hospital and community employees, 1994-96

\begin{tabular}{|c|c|c|c|c|c|c|c|c|}
\hline \multirow[b]{2}{*}{ Time* } & \multicolumn{3}{|c|}{ Hospital employees } & \multicolumn{3}{|c|}{ Community employees } & \multirow[b]{2}{*}{$p$ Valuet } & \multirow{2}{*}{$\begin{array}{l}\text { Odds } \\
\text { ratiof }\end{array}$} \\
\hline & $n$ (quit/total) & Quit ratio & $95 \% C I$ & $n$ (quit/total) & Quit ratio & $95 \% C I$ & & \\
\hline 6 months & $24 / 816$ & 0.030 & $(0.018$ to 0.041$)$ & $17 / 1033$ & 0.016 & (0.009 to 0.024$)$ & 0.115 & 1.66 \\
\hline 1 year & $42 / 808$ & 0.052 & (0.037 to 0.067$)$ & $30 / 1026$ & 0.029 & (0.019 to 0.039$)$ & 0.019 & 1.77 \\
\hline 18 months & $48 / 803$ & 0.088 & (0.069 to 0.108$)$ & $71 / 1018$ & 0.047 & (0.034 to 0.060$)$ & 0.001 & 1.97 \\
\hline 2 years & $75 / 766$ & 0.098 & (0.077 to 0.118$)$ & $62 / 1013$ & 0.061 & (0.047 to 0.076$)$ & 0.003 & 1.72 \\
\hline 3 years & $101 / 695$ & 0.145 & ( 0.120 to 0.171$)$ & $88 / 952$ & 0.092 & (0.075 to 0.110$)$ & 0.001 & 1.68 \\
\hline 4 years & $120 / 625$ & 0.192 & (0.162 to 0.222$)$ & $93 / 783$ & 0.119 & (0.097 to 0.141$)$ & 0.001 & 1.83 \\
\hline 5 years & $106 / 472$ & 0.225 & (0.188 to 0.261$)$ & $94 / 602$ & 0.156 & (0.128 to 0.184$)$ & 0.005 & 1.58 \\
\hline 6 years & $90 / 323$ & 0.279 & ( 0.231 to 0.326$)$ & $53 / 377$ & 0.141 & (0.107 to 0.175$)$ & 0.001 & 2.40 \\
\hline 7 years & $43 / 168$ & 0.256 & (0.192 to 0.319$)$ & $27 / 190$ & 0.142 & (0.093 to 0.191$)$ & 0.020 & 1.91 \\
\hline 8 years & $18 / 78$ & 0.231 & $(0.141$ to 0.321$)$ & $20 / 94$ & 0.213 & (0.134 to 0.291$)$ & 0.762 & 1.12 \\
\hline 9 years & $6 / 15$ & 0.400 & (0.152 to 0.648$)$ & $5 / 23$ & 0.217 & (0.049 to 0.386$)$ & 0.231 & 2.40 \\
\hline
\end{tabular}

$\star$ Time 0 is not the same for each respondent since all bans were not implemented at the same time. Consequently, time is not cross-sectional across all respondents.

†For hospital employees compared with community employees. All odds ratios are adjusted for hospital-community pairings.

CI, confidence interval 


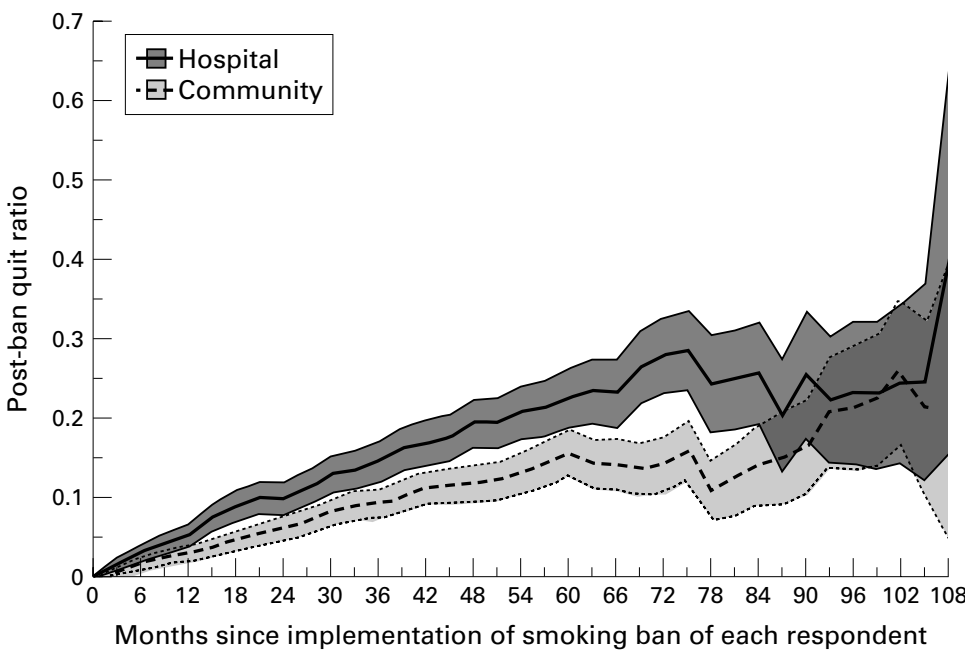

Figure 1 Cox proportional hazards model of post-ban quit ratio by time since implementation of smoking ban, US hospital and community employees, 1994-96. The area around each line represents the $95 \%$ confidence limits. A given time since implementation of smoking ban on the $x$ axis does not represent a single date, but time since implementation of smoking ban for each respondent. Bans were implemented in different hospitals on different dates.

Table 2 Cox proportional hazards model predicting time to quit smoking, US hospital and community employees, 1994-96

\begin{tabular}{|c|c|c|c|c|}
\hline Variable & $\begin{array}{l}\text { Parameter } \\
\text { estimate (B) }\end{array}$ & $p$ Value & $\begin{array}{l}\text { Hazard } \\
\text { ratio }\end{array}$ & $95 \% C I$ \\
\hline Hospital employee & 0.83 & 0.0001 & 2.29 & (1.556 to 3.368$)$ \\
\hline Employee/group & & 0.52 & & \\
\hline Blue collar & 0.18 & & 1.20 & (0.762 to 1.895$)$ \\
\hline Clerical & 0.32 & & 1.38 & ( 0.790 to 2.407 ) \\
\hline White collar & 0.0 & & 1.0 & \\
\hline Education & & 0.006 & & \\
\hline High school or less & 0.0 & & 1.0 & \\
\hline Technical & 0.20 & 0.58 & 1.22 & (0.608 to 2.451$)$ \\
\hline College & 0.56 & 0.006 & 1.76 & (1.177 to 2.622 ) \\
\hline Graduate & 1.04 & 0.001 & 2.82 & (1.493 to 5.331$)$ \\
\hline Age & 0.001 & 0.89 & 1.001 & (0.985 to 1.018$)$ \\
\hline Middle class & 0.28 & 0.13 & 1.33 & (0.919 to 1.913$)$ \\
\hline Female sex & -0.167 & 0.41 & 0.85 & (0.57 to 1.26$)$ \\
\hline
\end{tabular}

slightly to 2.3 (95\% CI 1.6 to 3.4 ), but it remained significant $(\mathrm{p}<0.001)$.

The proportion of hospital employees no longer smoking increased over the three surveys (fig 2). There was a significant difference between surveys 1 and $2(\mathrm{p}=0.005)$

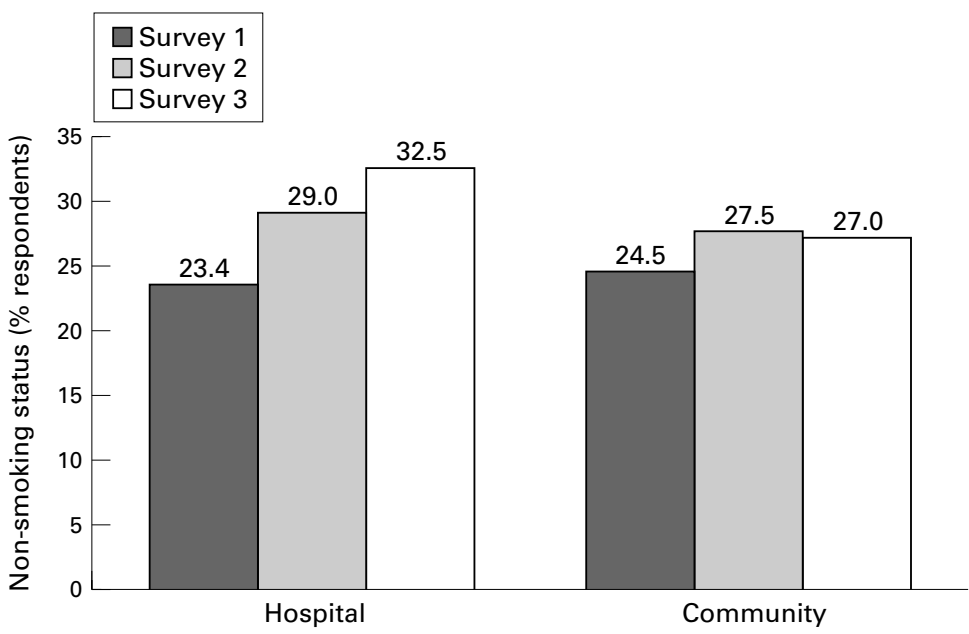

Figure 2 Smoking status of US hospital and community employees, 1994-96 ( $n=576$ ). For hospital employees, difference between years 1 and $2, p=0.005$; years 2 and $3, p=$ 0.001 . For community employees, difference between years 1 and $2, p=0.24$; years 2 and $3, p=0.35$. and surveys 1 and $3(\mathrm{p}<0.0001)$ in these proportions. In contrast, the proportion of community employees not smoking increased only slightly over the three years and there was no significant difference between surveys 1 and $2(\mathrm{p}=0.24)$ or between surveys 1 and 3 $(\mathrm{p}=0.35)$.

Of those respondents who were still smoking at the time of the first survey, $13.2 \%$ of the hospital employees and $10.6 \%$ of the community employees had quit smoking at survey 2 . At survey 3,17.7\% of the hospital employees and $11.3 \%$ of the community employees had quit smoking. There was no significant difference between the groups at survey 2 $(p=0.59)$. However, there was a significant difference at survey $3(\mathrm{p}=0.05)$.

Of those respondents who were not smoking at the time of the first survey, $19.3 \%$ of the hospital employees and $20.4 \%$ of the community employees had resumed smoking at survey 2. At survey 3, $19.3 \%$ of the hospital employees and $24.5 \%$ of the community employees had relapsed relative to year 1 . There was no significant difference between the groups at either survey $2(p=0.72)$ or survey 3 $(\mathrm{p}=0.63)$.

\section{Discussion}

Compared with employees working in settings where smoking is allowed, more employees of hospitals with total smoking bans quit smoking. The within-group changes were notable. For example, within the hospital employee group, there were significant differences in smoking status between surveys 1 and 2 and surveys 1 and 3 . Within the community employee group, there was no significant difference between surveys 1 and 2 or surveys 1 and 3 . These findings provide evidence that a cross-sectional survey may not provide a good indication of overall smoking ban impact on cessation, as even within-group results differ. The impact of time of measurement, duration of ban, duration of smoking cessation efforts, as well as their relations to the overall cessation cycle may greatly influence cross-sectional findings and point to the need for this prospective study.

The consistency between and within the two groups suggests that the two employee groups are not as dissimilar as might be expected given their place of employment. For example, while hospitals are the largest employer of nurses, the smoking rate among nurses is similar to the US female smoking rate. ${ }^{31}$ In 1990-91, $18.3 \%$ of registered nurses were current smokers, compared with $27.2 \%$ of licensed practical nurses. $^{32}$ The age adjusted prevalence of current smoking for all US women age 18 and over was $23 \%$ in $1993 .{ }^{33}$ Further, many of the job categories (such as secretaries and maintenance workers) found in hospitals are similar to those found in other US businesses. This, together with our inclusion of relevant covariates in the model, should address concerns that this study may potentially raise in terms of generalisability. However, as in any study of this type, potential limitations and cautions must be made. 
There are several limitations to this study. First, we must emphasise that this study is based on a "natural experiment", the issuance of tobacco control standards by the JCAHO, and as such it is a quasi-experimental design. By eliminating the features and benefits of a randomised experiment, the ability to control for unmeasured confounders is lost. Nevertheless, there is a great deal that can be learned from a study of such design. In particular, in the area of policy research it permits the investigator to take full advantage of a naturally occurring event that could help shape public debate and policy. Thus, while we cannot claim that workplace bans cause smokers to quit, we can report that there is a statistical association that should be further explored.

There is a possibility that the quit rates could have been the same for the two groups in the study in absence of the smoking bans. However, our model took into account the preban smoking intensity and we used phone numbers to select community workers that lived near hospital employees. There is also the possibility that the two populations may be dissimilar; in our comparison of the two groups we found several characteristics that were dissimilar and adjusted for these in the model. Additionally, our review of the literature and related data indicates that when physicians are eliminated from the population of hospital employees, the remaining employees are similar to the general population in their smoking rates.

Finally, it is possible that there may be recall bias in smokers' ability to cite a quit date. It seems unlikely that one group's recollection was more dependable than the other's. Previous work indicates that such recall bias is small and may not be a problem given the questions we used were adopted from the Behavioral Risk Factor Surveillance Survey, which has been tested and found reliable and valid, ${ }^{34-36}$ and from the work of the National Heart, Lung, and Blood Institutes. ${ }^{24} 257$

The widespread adoption of total workplace bans could have major beneficial health effects. Indeed if there are to be further reductions in morbidity and mortality from smoking behaviour, interventions such as workplace bans that may provide cost effective ways to reduce smoking prevalence and eliminate exposure to workplace hazards, such as environmental tobacco smoke, should be considered. Since in most developed countries adults spend a considerable amount of their waking hours in the workplace, workplace behaviour may have an effect on behaviour out of the workplace. Similar results are found in smaller cross-section studies in southern Germany, ${ }^{8}$ Spain, ${ }^{9}$ France, ${ }^{38}$ Japan, ${ }^{39}$ Australia, ${ }^{11}$ and the USA. ${ }^{14}{ }^{15} 40-42$ Therefore our results have application internationally, particularly in developed countries with similar workplace and employment conditions. Our study provides added support for the positive impact of working smoking bans on the health of employees.

\section{What this paper adds}

There is some evidence that workplace smoking bans lower smoking rates among employees, but most studies are crosssectional and examine only one workplace. Little is known about the long term effects of smoking bans on cessation and relapse.

We studied employees of 12 hospitals across the USA where smoking was banned. Compared with employees in the same community in workplaces where smoking was allowed, quit rates were higher and time to quit smoking was shorter among employees of hospitals with smoking bans. Relapse rates were similar between the two groups.

Workplace smoking bans provide another opportunity to encourage smoking cessation and should be considered in the arsenal of strategies to reduce and prevent smoking among adults.

The Robert Wood Johnson Foundation's Tobacco Control Policy Program, Princeton, New Jersey (grant 22931), helped to fund this study. Funding for additional analyses and writing was made available through the American Academy of Family Practice which supplies funds for the Center for Family Medicine Science in the Department of Family and Community Medicine, University of Missouri-Columbia (UM-C), Columbia, MO. We are grateful to the hospitals, their employees, and community members who participated in this study. We are also grateful to Shari Schubert, Wendy Luttrell, and Orah Mockbee of UM-C for their administrative and clerical assistance.

1 Davis RM. Passive smoking: history repeats itself. $B M F$ 1997;315:961-2.

2 Law MR, Morris JK, Wald NJ. Environmental tobacco smoke exposure and ischaemic heart disease: an evaluation of the evidence. BMF 1997;315:973-80.

3 Hackshaw AK, Law MR, Wald NJ. The accumulated evidence on lung cancer and environmental tobacco smoke. BMF 1997;315:980-8.

4 Nyberg F, Pershagen G. Passive smoking and lung cancer. Accumulated evidence on lung cancer and environmental tobacco smoke. BMF 1998;317:347-8.

5 World Health Organization. Combating the tobacco epidemic. World health report 1999: making a difference. Geneva: WHO, 1999:65-79.

6 Longo DR, Brownson RC, Kruse RL. Smoking bans in U.S hospitals: results of a national survey. $\mathscr{\text { }} A M A$ 1995; hospitals: resu

7 Howard G. Passive smoking - some further legal issues for employers. Br f Addict 1992;87:695-701.

8 Brenner H, Fleischle B. Smoking regulations at the workplace and smoking behavior: a study from southern Germany. Prev Med 1994;23:230-4.

9 Bonfill X, Serra C, Lopez V. Employee and public responses to simulated violations of no-smoking regulations in Spain. Am f Public Health 1997;87:1035-7.

10 Borland R, Owen N, Hill D, et al. Predicting attempts and sustained cessation of smoking after the introduction of workplace smoking bans. Health Psychol 1991;10:336-42.

11 Borland R, Chapman S, Owen N, et al. Effects of workplace smoking bans on cigarette consumption. Am f Public Health 1990;80:178-80.

12 Lang T, Nicaud V, Slama $\mathrm{K}$, et al. Smoking cessation at the workplace. Results of a randomised controlled intervention study. Worksite physicians from the AIREL group. $\mathcal{F}$ Epidemiol Community Health 2000;54:349-54.

13 Parrott S, Godfrey C, Raw M. Costs of employee smoking in the workplace in Scotland. Tobacco Control 2000;9:187-92.

14 Chapman S, Borland R, Scollo M, et al. The impact of smoke-free workplaces on declining cigarette consumption in Australia and the United States. Am f Public Health 1999;89:1018-23.

15 Farrelly MC, Evans WN, Sfekas AE. The impact of workplace smoking bans: results from a national survey. Tobacco Control 1999;8:272-7.

16 Shumaker SA, Grunberg NE, eds. Proceedings of the National Working Conference on Smoking Relapse. Health Psychol 1986;5 supplement.

17 Ossip-Klein DJ, Bigelow G, Parker SR, et al. Classification and assessment of smoking behavior. Health Psychol 1986; 5(suppl):3-11.

18 Centers for Disease Control and Prevention. Smoking cessation during previous year among adults-United cessation during previous year among adults-United
States, 1990 and 1991. MMWR Morb Mortal Wkly Rep 1993;42:504-7.

19 Longo DR, Brownson RC, Johnson JC, et al. Hospital smoking bans and employee smoking behavior: results of a national survey. $\mathcal{F A M A}$ 1996;275:1252-7. 
20 Gottlieb NH, Eriksen MP, Lovato CY, et al. Impact of a restrictive work site smoking policy on smoking behavior, restrictive work site smoking policy on smoking beh
attitudes, and norms. $\mathcal{F}$ Occup Med 1990;32:16-23.

21 American Hospital Association. Hospital statistics. Chicago, Illinois: Healthcare InfoSource, American Hospital Association, 2001

22 Emont SL, Zahniser SC, Marcus SE, et al. Evaluation of the 1990 Centers for Disease Control and Prevention smokefree policy. Am f Health Promot 1995;9:456-61.

23 Brownson RC, Jackson-Thompson J, Wilkerson JC, et al. Demographic and socioeconomic differences in beliefs about the health effects of smoking. Am $\mathcal{F}$ Public Health 1992;82:99-103.

24 Gentry EM, Kalsbeek ED, Hogelin GC. The behavioral risk factor surveys: II. Design, methods, and estimates from combined state data. Am f Prev Med 1985;1:9-14.

25 Remington PL, Smith MY, Williamson DF, et al. Design, characteristics, and usefulness of state-based behavioral characteristics, and usefulness of state-based behavioral
risk factor surveillance. Public Health Rep 1988;103:36675 .

26 US Department of Health and Human Services. Smoking and health, a national status report: a report to Congress, 2nd ed. Rockville, Maryland: Centers for Disease Control, Office on Smoking and Health, 1990. (DHHS Publication No (CDC) 87-8396.)

27 US Department of Health and Human Services. Reducing the health consequences of smoking: 25 years of progress. A report of the Surgeon General, 1989. Rockville, Maryland: Public Health Service, Centers for Disease Control, Office on Smoking and Health, 1989. (DHHS Publication No (CDC) 89-8411.)

28 Landis RJ, Heyman ER, Koch GG. Average partial association in three-way contingency tables: a review and discussion of alternative tests. Int Stat Rev 1978;46:237-54.

29 Kalbfleisch JD, Prentice RL. The statistical analysis of failure time data. New York: Wiley; 1995.

30 Longo DR, Feldman MM, Kruse RL, et al. Implementing smoking bans in American hospitals: results of a national smoking bans in American hospitals:
survey. Tobacco Control 1998;7:47-55.

31 Kamimoto LA, Easton AN, Maurice E, et al. Surveillance for five health risks among older adults-United States, for five health risks among older adults-United States,
1993-1997. MMWR Morb Mortal Wkly Rep CDC Surveillance Summaries 1999;48(SS08):89-130.
32 Nelson DE, Giovino GA, Emont SL, et al. Trends in cigarette smoking among U.S physicians and nurses. cigarette smoking amon
$7 A M A 1994 ; 271: 1273-5$.

33 National Center for Health Statistics. Cigarette smoking; figure 20. Current cigarette smokers among person 18 years of age and over by sex: United States, 1965-93. In: National Center for Health Statistics (US), ed. Health, United States, 1995. Hyattsville, Maryland: US Department of Health and Human Services, Public Health Service, Centers for Disease Control, National Center for Health Statistics, 1996:36.

34 Brownson RC, Jackson-Thompson J, Wilkerson JC, et al. Reliability of information on chronic disease risk factors collected in the Missouri behavioral risk factor surveillance system. Epidemiology 1994;5:545-9.

35 Jackson C, Jatulis DE, Fortmann SP. The behavioral risk factor survey and the Stanford five-city project survey: a comparison of cardiovascular risk behavior estimates. Am comparison of cardiovascular ris

36 Shea S, Stein AD, Lantigua R, et al. Reliability of the behavioral risk factor survey in a triethnic population. Am F Epi-

37 Brownson RC, Jackson-Thompson J, Wilkerson JC, et al. Demographic and socioeconomic differences in beliefs about the health effects of smoking. Am F Public Health 1992;82:99-103.

38 Hill C. Trends in tobacco smoking and consequences on health in France. Prev Med 1998;27:514-19.

39 Mizoue T, Reijula A, Yamato H, et al. Support for and observance of worksite smoking restriction policies-a study of municipal employees at a city office in Japan. Prev Med 1999;29(6 Pt 1):549-54.

40 Pierce JP, Gilpin EA, Farkas AJ. Can strategies used by statewide tobacco control programs help smokers make progress in quitting? Cancer Epidemiology, Biomarkers \& Prevention 1998;7:459-64.

41 Emmons KM, Thompson B, McLerran D, et al. The relationship between organizational characteristics and the adoption of workplace smoking policies. Health Educ Behav 2000;27:483-501.

42 Moskowitz JM, Lin Z, Hudes ES. The impact of workplace smoking ordinances in California on smoking cessation. Am f Public Health 2000;90:757-61.

Where have all the smokers gone?

Paul Hackett, of Lane Cove in Sydney, had just sat down for the 7.30 am Mass at Riverview College on Sunday when there was an announcement from the assistant to the parish priest. Did anyone in the congregation have matches or a cigarette lighter to light the candles? Pockets were patted and handbags searched, to no avail. Someone went over to the college, returning about five minutes into the Mass to light the candles. Mr Hackett thinks that, had there been a similar request a decade ago, about a third of the congregation could have coughed up a light.

Source: Sydney Morning Herald 10 fuly 2001 